Proceeding

\title{
Is patenting medical devices still viable?
}

\section{Proceeding}

In the last century surgeons like Homer Stryker invented devices and prosthetics that were of benefit to their patients and allowed them to work safely and efficiently. Many great ideas were patented and licensed. Manufacturing investment was made on the basis of clever patents that delivered better outcomes. This system of invention, patenting, manufacture and protected retail sales enabled multinational corporations to grow and prosper. However, now the cost and waste of this over regulated and over protected industry is spiraling out of control.

In the 21 st century disruptive additive manufacturing (AM) and real time online biomedical engineering has now completely changed the paradigm. Personalised healthcare allows patient data to be used to manufacture patient specific devices and prosthetics using community based distributed manufacturing. Now a 'build code' can be used to make the same device on the same 3D printer anywhere in the world! Surgeons can share such codes to help their patients whilst improving efficiency and outcomes at lower cost! Such sharing of build codes may well infringe patent or copyright laws.

For the benefit of a patient in need would/could such IP be defended if a hospital prints the part? Wouldn't many build codes be unique and without 'patenting value' anyway? Why waste expense and time if
Volume 4 Issue 2 - 2017

\section{Paul S D’Urso}

Neurosurgeon, University of Queensland, Australia

Correspondence: Paul S D'Urso, Neurosurgeon, University of Queensland Melbourne,Australia, Email paul@pauldurso.com

Received: March II, 2017 | Published: March 23, 2017

designs are changing so rapidly? It is now easy for a surgeon to 'laser scan' an object and print it in their Solution Centre. How could patent and copyright laws be enforced in this situation?

Once inventive surgeons come to understand that they can innovate using the Anatomics Rx Solutions Portal they will be delighted to share their designs and case studies on the Diversity platform. If such designs are popular the surgeon will be recognised and receive Diversity points and credits. Healthcare workers, students and teachers can now share ideas and innovation without the need for patents as they develop quality Community Based Personalised Healthcare that is affordable and sustainable (Figure 1).

Figure I US medical device patents.

\section{Acknowledgements}

None.

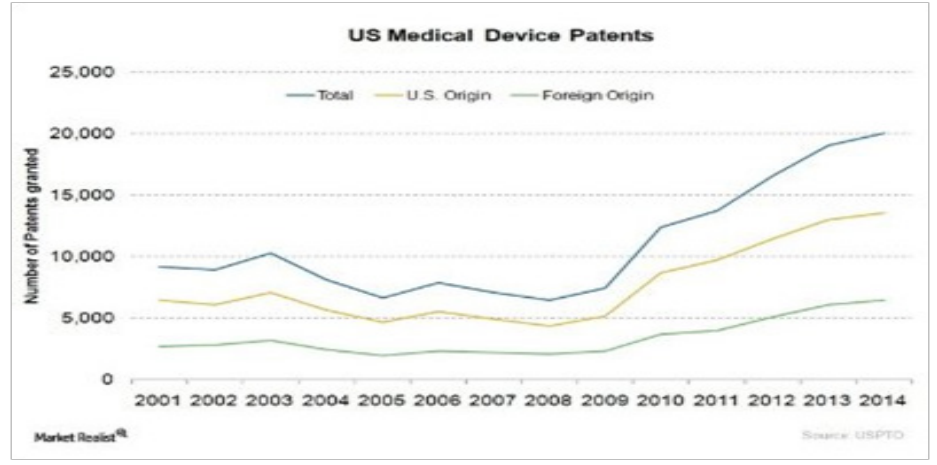

\section{Conflict of interest}

The author declares no conflict of interest. 